\title{
Extra copies of chromosome 2 are a recurring aberration in ALK-negative lymphomas with anaplastic morphology
}

\author{
Rina Kansal ${ }^{1,4}$, Sheila NJ Sait ${ }^{2}$, AnneMarie W Block ${ }^{2}$, Pamela M Ward ${ }^{3}$, Felicity LR Kelly², \\ Richard T Cheney ${ }^{4}$, Myron Czuczman ${ }^{5}$, Martin L Brecher ${ }^{6}$ and Maurice Barcos ${ }^{4}$ \\ ${ }^{1}$ Department of Pathology, Buffalo General Hospital, The State University of New York, Buffalo, NY, USA; \\ ${ }^{2}$ Clinical Cytogenetics Laboratory; ${ }^{3}$ Molecular Diagnostics Laboratory; ${ }^{4}$ Department of Pathology and \\ Laboratory Medicine; ${ }^{5}$ Department of Medicine and ${ }^{6}$ Department of Pediatrics, Roswell Park Cancer Institute, \\ Buffalo, NY, USA
}

\begin{abstract}
The purpose of this study was to evaluate fluorescence in situ hybridization abnormalities of the $2 p 23$ anaplastic lymphoma kinase (ALK) gene loci in lymphomas with anaplastic morphology. We studied 24 anaplastic large cell lymphomas (ALCL) classified by World Health Organization criteria [17 primary nodal/ systemic (10 ALK +, 7 ALK-), seven primary cutaneous], and 17 additional non-Hodgkin's lymphomas [one ALK + B-lineage lymphoma, 14 ALK - diffuse large B-cell lymphomas (seven anaplastic variants, five nonanaplastic, two secondary $\mathrm{CD} 30+$ ), two follicular lymphomas]. ALK - lymphomas with anaplastic morphology showed extra nonrearranged anaplastic lymphoma kinase gene loci $(P=0.004)$ due to trisomy 2 irrespective of the following factors: $B$ or T/null phenotype $(P=0.315)$, diagnostic categories of systemic or cutaneous ALCL or the above-mentioned B-cell lymphomas $(P=0.131)$, and CD30 positivity by immunohistochemistry $(P=1.000)$. Trisomy 2 was absent in all ALK + lymphomas $(P=0.009)$, which showed rearranged $A L K$ gene loci $(P<0.001)$. Whether trisomy 2 is a primary or secondary event that leads to ALK- lymphomas cannot be determined from this study. Its presence in secondary B-cell lymphomas suggests that trisomy 2 may be a secondary cytogenetic aberration in lymphomas in general. Further investigation of this finding is necessary to further our understanding of the heterogeneous group of ALK-lymphomas.

Modern Pathology (2005) 18, 235-243, advance online publication, 8 October 2004; doi:10.1038/modpathol.3800299
\end{abstract}

Keywords: anaplastic large cell lymphoma; ALK; anaplastic lymphoma kinase; ALK-positive B-cell lymphoma; fluorescence in situ hybridization; trisomy 2

Anaplastic large cell lymphomas (ALCL) were originally described ${ }^{1}$ as a large cell lymphoma with a characteristic cytomorphology and preferential paracortical and intrasinusoidal involvement of lymph nodes, in which virtually all neoplastic cells were strongly positive for the Ki-1 (CD30) antibody. Since then, a number of morphologic variants have been described. ${ }^{2-9}$ Clinically, ALCL include primary systemic ALCL, primary cutaneous ALCL, HIVrelated ALCL, or forms secondary to another lymphoproliferative disorder. ${ }^{10,11}$ According to the Revised European-American and World Health Organization (WHO) classifications of lymphoid

Correspondence: Dr M Barcos, MD, PhD, Department of Pathology and Laboratory Medicine, Roswell Park Cancer Institute, Elm \& Carlton Streets, Buffalo, NY 14263, USA.

E-mail: maurice.barcos@roswellpark.org

Received 7 July 2004; revised and accepted 26 August 2004; published online 8 October 2004 neoplasms, the diagnosis of ALCL is restricted to T/null-cell lymphomas, ${ }^{12}$ the majority of which express the anaplastic lymphoma kinase (ALK) protein and demonstrate clonal rearrangement of the T-cell receptor genes. ${ }^{13}$ Primary systemic ALCL include ALK + and ALK - cases, with ALK + cases comprising a distinct entity with favorable prognostic significance. ${ }^{13-16}$ Whether ALK- ALCL cases are a variant of ALK + ALCL or a different clinicopathologic entity is not clear at this time. ${ }^{13}$ Anaplastic large B-cell lymphomas, as recognized by the Kiel classification, ${ }^{17}$ are considered to be an anaplastic variant of diffuse large B-cell lymphomas. ${ }^{13,18}$ Rare ALK + diffuse large B-lineage lymphomas have also been described, ${ }^{19}$ and shown to have 2p23 anaplastic lymphoma kinase gene $(A L K)$ translocations,${ }^{20-22}$ similar to those present in ALCL. ${ }^{23-26}$

The purpose of this study was to examine the 2p23 ALK loci by fluorescence in situ hybridization 
(FISH) on paraffin-embedded sections of ALK + and ALK - lymphomas with anaplastic morphology, including cases classified as ALCL and non-ALCL by WHO criteria. We identified extra copies of nonrearranged $2 \mathrm{p} 23 A L K$ loci as a novel recurring chromosomal aberration in ALK- lymphomas with anaplastic morphology, including ALCL and nonALCL, suggesting a common pathogenetic pathway in the heterogeneous group of ALK- lymphomas.

\section{Materials and methods}

\section{Cases (ALCL and Non-ALCL)}

The surgical pathology database at Roswell Park Cancer Institute was searched for ALCL and ALK+ lymphomas. Cases included on the basis of histopathologic features and CD30 positivity, as originally described by Stein et $a l^{1}$ were reclassified according to WHO criteria. The following 24 ALCL cases were included: 15 primary systemic nodal/ extranodal ALCL (10 ALK+, five ALK-) in 15 patients (three pediatric and 12 adults; nine males and six females; 11 nodal and four extranodal: lung, small bowel, bone and soft tissue), two recurrences of ALK - primary systemic ALCL, and seven cutaneous ALCL in six adult patients (five males, one female). The cutaneous ALCL cases included two recurrences. The histopathology of the majority of cases of primary systemic nodal/extranodal ALCL was typical for the common variant of ALCL, likely a reflection of our study design for case retrieval. Our ALK + cases included a majority $(n=6)$ with sole cytoplasmic ALK positivity, and four with both cytoplasmic and nuclear positivity. All cutaneous ALCL cases showed histologic features consistent with ALCL, that is, sheets of large lymphoma cells infiltrating the dermis, with subcutaneous fat involvement. The primary systemic ALCL cases did not have a prior clinical history of a lymphoproliferative disorder by review of the patients' medical records. The cases of primary cutaneous ALCL did not have a history of any systemic/nodal disease for 1 year after diagnosis by clinical or radiologic examination. Most of our cases were referred from other institutions.

The non-ALCL cases included one ALK + nodal diffuse large B-lineage lymphoma and 17 ALKlymphomas [14 diffuse large B-cell lymphomas in 14 patients (five CD30 + and two CD30- cases with anaplastic histologic features, five nonanaplastic, two secondary CD30 + composite lymphomas), two follicular lymphomas, and the primary component within one of the above-mentioned composite lymphomas]. The composite lymphomas included one diffuse large B-cell lymphoma, anaplastic variant coexistent with follicular lymphoma, grade 1, and one large B-cell lymphoma with nodular lymphocyte predominant Hodgkin lymphoma. ${ }^{27,28}$ The nodular Hodgkin component in the latter case was available for FISH study, while the paraffin block corresponding to the primary component in the other composite case was not available for study.

The diagnostic hematoxylin and eosin (H\&E) stained and immunohistochemical-stained sections were reviewed in all cases (RK, MB). The cases of primary cutaneous ALCL were also reviewed by our dermatopathologist (RTC). Paraffin section immunohistochemical stains performed using either the Ventana ES or DAKO autostainer included CD3 (polyclonal), CD4 (clone 1F6), CD5 (clone CD5/54/ F6), CD7 (clone 8H8.1), CD8 (clone C8/144B), CD15 (clones DTD7 and BC97), CD20 (clone L26), CD30 (clone Ber-H2), CD45RO (clone UCHL-1), CD79a (clone HM57), EMA (clone E29), ALK1 (clone ALK1), and the cytotoxic cell-associated markers TIA-1 (clone TIA-1) and Granzyme B (clone GrB-7). Stains for CD138 (clone MI15), IgM (polyclonal), IgG (polyclonal), IgA (polyclonal), and $\kappa$ (polyclonal) and $\lambda$ (polyclonal) immunoglobulins were performed in the case of ALK + diffuse large B-lineage lymphoma. All antibodies were obtained from DAKO (Carpinteria, CA, USA), except for CD30, CD15, TIA-1 (Biocare Medical, Walnut Creek, CA, USA), CD4 (Novocastra, Vector Laboratories, Burlingame, CA, USA), CD7 (Immunotech, Inc., Westbrook, ME, USA), and GrB-7 (Serotec Ltd, Raleigh,

Table 1 Immunohistochemical features of primary systemic nodal/extranodal and primary cutaneous ALCL, and the ALK+ diffuse large B-lineage lymphoma

\begin{tabular}{|c|c|c|c|c|c|c|c|c|}
\hline & $\begin{array}{c}\text { Total } \\
\text { numbers } \\
\text { of } \\
\text { patients }\end{array}$ & $\begin{array}{c}\text { CD30 } \\
\text { positive }\end{array}$ & $\begin{array}{c}\text { CD15 } \\
\text { positive }\end{array}$ & $\begin{array}{c}\text { ALK } \\
\text { positive }\end{array}$ & $\begin{array}{c}E M A \\
\text { positive }\end{array}$ & $\begin{array}{c}\text { TIA-1 } \\
\text { and/or } \\
\text { granzyme } \\
\text { B positive }\end{array}$ & $\begin{array}{l}\text { T-cell antigens } \\
\text { positive }\end{array}$ & Other \\
\hline $\begin{array}{l}\text { Primary systemic nodal/ } \\
\text { extranodal ALCL }\end{array}$ & 15 & $15 / 15$ & $0 / 9$ & $10 / 15$ & $3 / 8$ & $11 / 15$ & $13 / 15$ & Not applicable \\
\hline Primary cutaneous ALCL & 6 & $6 / 6$ & $\begin{array}{c}\text { Not } \\
\text { available }\end{array}$ & $0 / 6$ & $\begin{array}{c}\text { Not } \\
\text { available }\end{array}$ & $2 / 5$ & $6 / 6$ & Not applicable \\
\hline $\begin{array}{l}\text { ALK+ diffuse large } \\
\text { B-lineage lymphoma }\end{array}$ & 1 & $0 / 1$ & $\begin{array}{c}\text { Not } \\
\text { available }\end{array}$ & $1 / 1$ & $\begin{array}{c}\text { Not } \\
\text { available }\end{array}$ & $\begin{array}{c}\text { Not } \\
\text { available }\end{array}$ & $\begin{array}{l}\text { 0/1 (CD3-CD4- } \\
\text { CD5-CD8-) }\end{array}$ & $\begin{array}{l}\text { CD138+, cytoplasmic } \\
\text { IgG+, IgA-, IgM-, } \lambda+, \\
\kappa-, \text { CD20-, CD79a- }\end{array}$ \\
\hline
\end{tabular}


NC, USA). Frozen section immunohistochemical stains for T-cell antigens were used for the determination of T-cell lineage in one case of primary cutaneous ALCL. The immunohistochemical features of the primary systemic and cutaneous ALCL and ALK + B-lineage lymphoma cases are summarized in Table 1. The pathologic features of the primary systemic ALCL and ALK + diffuse large Blineage lymphoma cases are illustrated in Figures 1a-f and $2 a-d$, respectively.
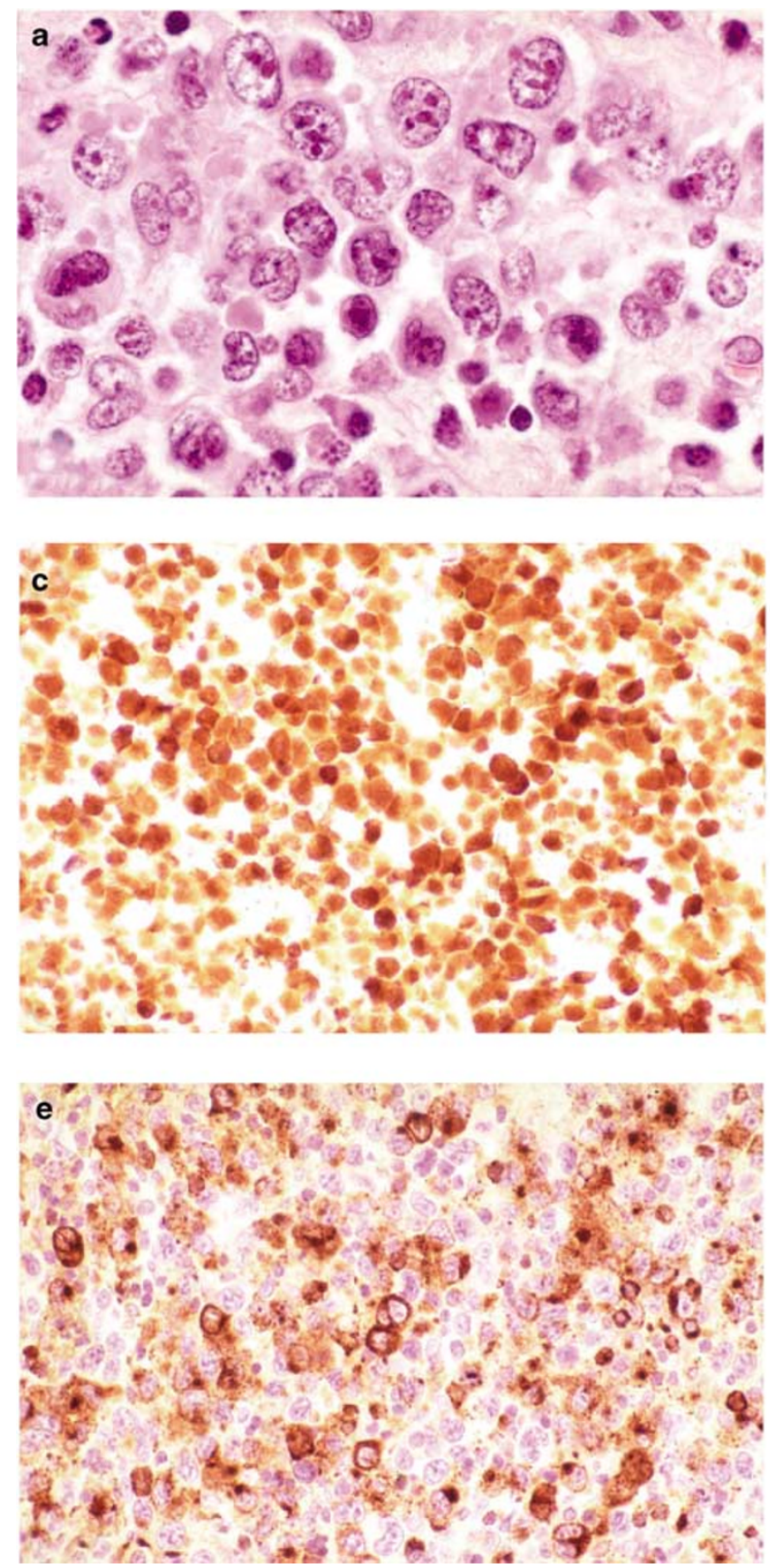

\section{FISH}

FISH was performed on formalin-fixed, paraffinembedded, $4 \mu \mathrm{m}$ tissue sections in 44 of 45 specimens and on a touch-imprint smear preparation in one specimen, using a commercially available dual-color, break apart rearrangement probe (LSI $A L K$, Vysis, Inc., Downer's Grove, IL, USA). This probe targets sequences on either side of the $\mathrm{t}(2 ; 5)(\mathrm{p} 23 ; \mathrm{q} 35)$ breakpoint of the $A L K$ gene (telo-
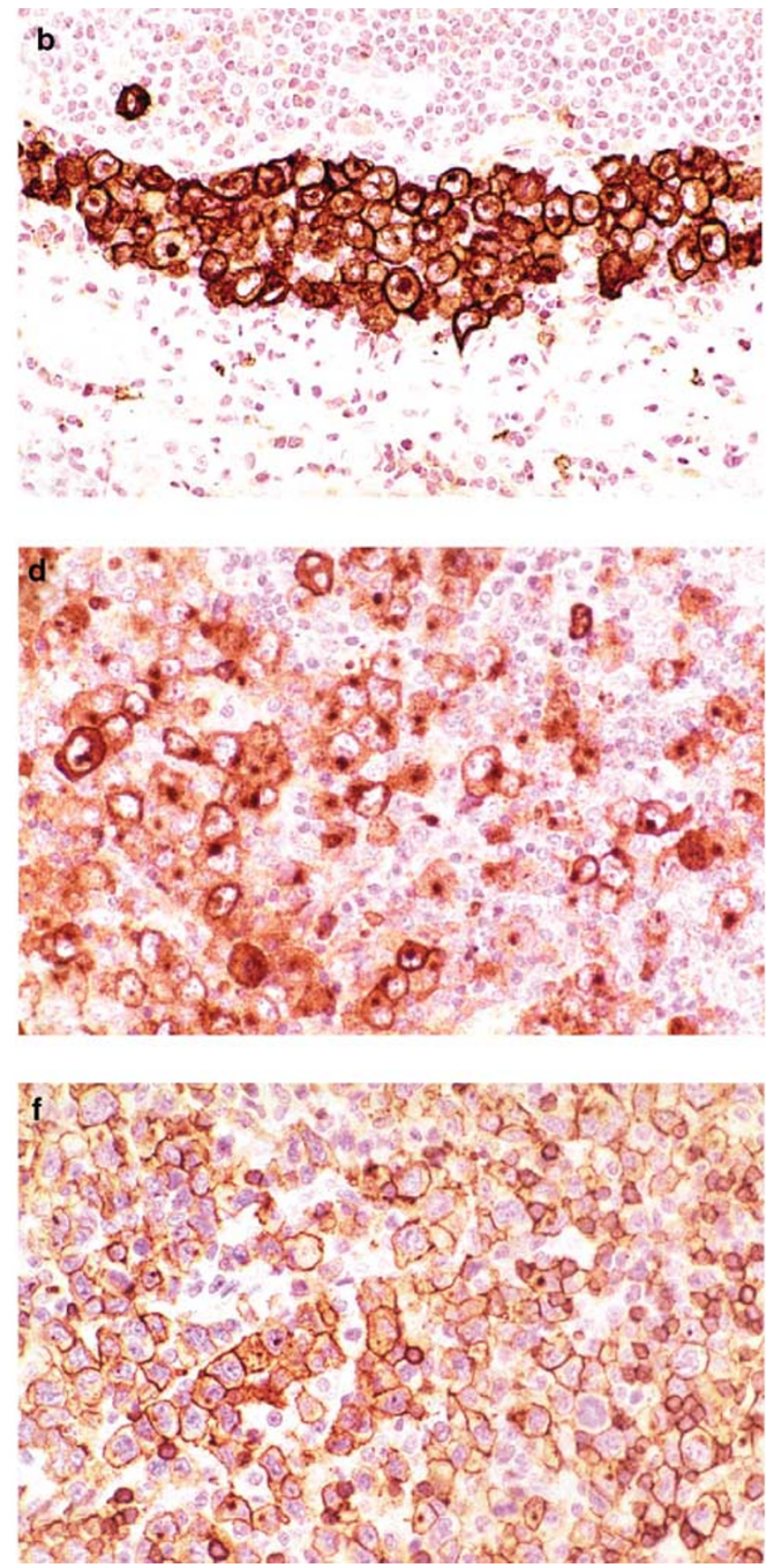

Figure 1 Primary systemic ALCL: (a) common histologic variant (H\&E, $\times 1000)$; (b) showing sinusoidal involvement by CD30+ lymphoma cells (membranous and Golgi zone pattern, $\times 400$ ); (c) showing ALK1 + lymphoma cells (nuclear and cytoplasmic staining pattern, $\times 400$ ); (d) with epithelial membrane antigen-positive lymphoma cells (membrane and Golgi zone staining pattern, $\times 400$ ); (e) with granzyme B-positive lymphoma cells $(\times 400)$; (f) with CD5-positive lymphoma cells $(\times 400)$. 

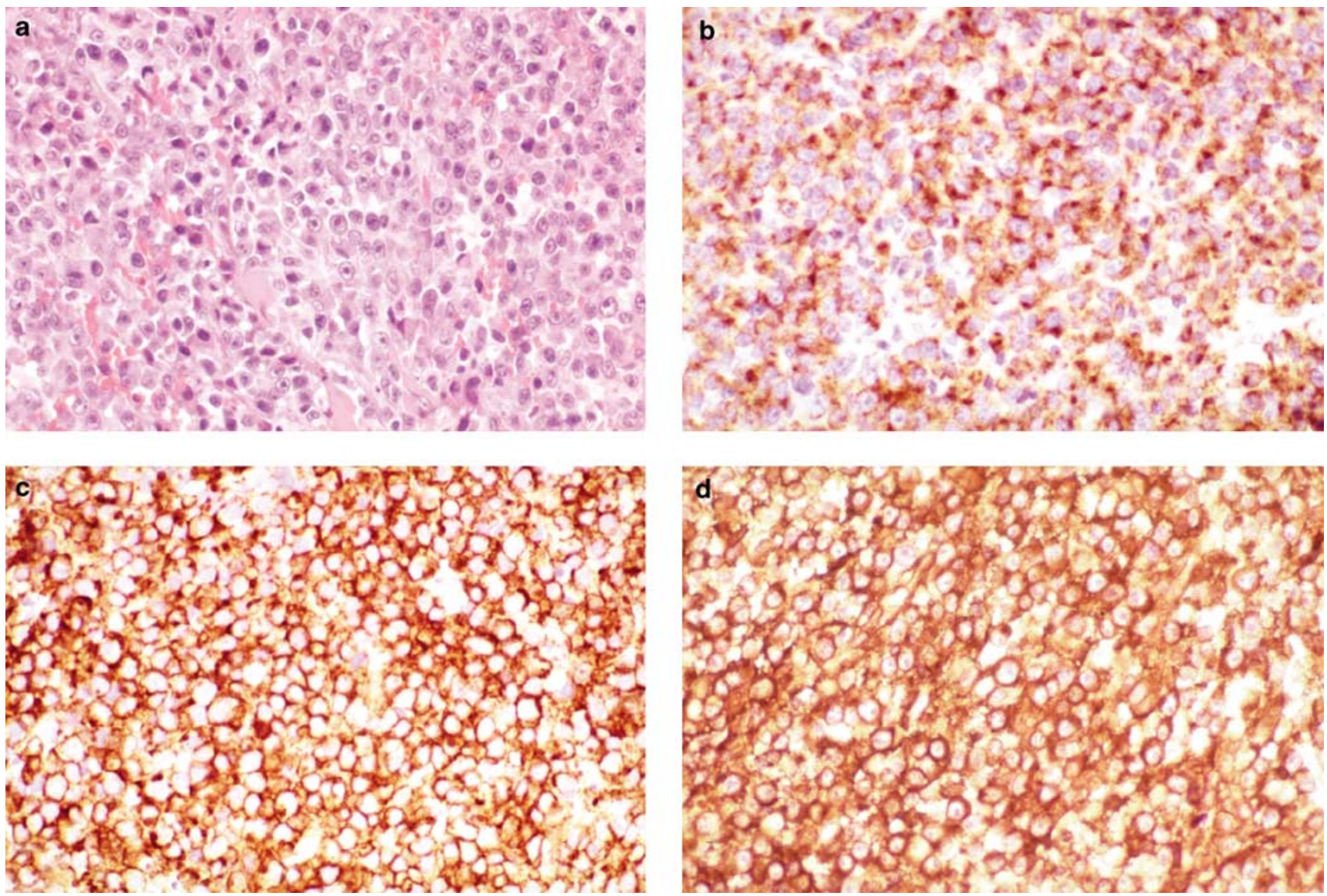

Figure 2 (a) Diffuse large B-lineage ALK + lymphoma (H\&E, $\times 400)$, showing cytoplasmic ALK1 immunopositivity in lymphoma cells in (b) $(\times 400)$, CD138 + lymphoma cells in (c) $(\times 400)$, and cytoplasmic IgG + lymphoma cells in (d) $(\times 400)$.

meric $250 \mathrm{~kb}$ SpectrumOrange and centromeric $300 \mathrm{~kb}$ SpectrumGreen probes) and detects $2 \mathrm{p} 23$ $A L K$ gene rearrangements, including variant translocations involving the same 2 p23 breakpoint as in the $\mathrm{t}(2 ; 5)(\mathrm{p} 23 ; \mathrm{q} 35)$ translocation. In cases that showed numerical abnormalities of the nonrearranged 2p23 ALK gene loci, additional FISH studies were performed using alpha satellite centromeric probes for chromosomes 2 and 10 (Vysis, Inc.). The probe for chromosome 10 was used as a control for evaluation for polyploidy, since trisomy 10 appears not to be commonly associated with the pathogenesis of lymphomas. Since the 2p23 locus-specific probe also detects aneusomy of chromosome 2 , the centromeric probes were not used in the cases with normal numbers of nonrearranged 2p23 loci. Sections from randomly selected small benign lymph nodes from two nonlymphoma patients and two ALCL study cases served as external negative FISH controls. Normal skin and small bowel epithelium served as negative internal FISH controls in the applicable cases.

The tissue sections were deparaffinized in a xylene substitute (Hemo De, Fisher Scientific), and prepared for FISH using a paraffin pretreatment reagent kit (Vysis, Inc.), as per the manufacturer's instructions. Subsequently, the probe and target DNA were codenaturated at $85^{\circ} \mathrm{C}$ for $1 \mathrm{~min}$, using the Hybrite system (Vysis, Inc.), and then hybridized at $37^{\circ} \mathrm{C}$ for $18-20 \mathrm{~h}$. The posthybridization washes were performed at $73 \pm 1^{\circ} \mathrm{C}$ for $2 \mathrm{~min}$ in $0.4 \times$ salinesodium citrate buffer (SSC) $/ 0.3 \%$ octylphenoxy polyethoxy ethanol (Nonidet P-40), followed by $2 \mathrm{X}$ SSC/0.1\% Nonidet P-40 at room temperature for $1 \mathrm{~min}$. The sections were counterstained with $4^{\prime}, 6-$ diamidino-2-phenylindole dihydrochloride (DAPI II, $125 \mathrm{ng} / \mathrm{ml}$, Vysis, Inc.) and then analyzed on a Nikon Optiphot-2 epifluorescence microscope (Nikon, Melville, NY, USA). The adequacy of hybridization was evaluated by examining the entire section, and representative lymphoma foci were identified for study by correlating with the corresponding H\&E sections. At least 20 high-power fields $(\times 1500$, oil) were studied using single, dual and triple bandpass filters (DAPI, SpectrumGreen, SpectrumOrange, Vysis, Inc.) in areas with minimal nuclear overlap. At least 500 nuclei with strong and well-delineated hybridization signals were examined by two observers (RK, SNJS). A set of immediately adjacent or fused orange/green signals 
was interpreted as a normal, non-rearranged 2p23 $A L K$ gene locus. Digitized images were captured using a monochrome CCD camera (Cohu Inc., San Diego, CA, USA) and image analysis software (MacProbe, Perceptive Scientific Instruments, Inc., League City, TX, USA).

\section{Statistical Analysis}

$\chi^{2}$ tests of significance were performed using the Statistical Package for the Social Sciences software for Windows, version 11.0 (SPSS, Inc., Chicago, IL, USA), to determine the significance of extra nonrearranged and rearranged 2p23 ALK gene loci in the study cases. For the purpose of statistical analysis, lymphomas with anaplastic morphology included all primary systemic ALK + and ALKALCL, all cutaneous ALCL and all anaplastic variants of diffuse large B-cell lymphoma (including the five CD30 + cases, two CD30- cases and the anaplastic $\mathrm{CD} 30+$ large B-cell components of the two composite lymphomas). The variables analyzed by statistical analysis included anaplastic vs nonanaplastic morphology, B- vs T/null cell phenotype, the WHO diagnostic categories of ALCL, cutaneous ALCL, diffuse large B-cell lymphoma (anaplastic variants and nonanaplastic) and follicular lymphoma, CD30 positivity, ALK1 positivity by immunohistochemistry and the sex of the patient. All $P$-values are two-sided and correspond to Fisher's exact test, wherever applicable. A $P$-value of less than 0.05 was considered statistically significant.

\section{Results}

\section{FISH}

FISH was successful in 18 ALCL and 17 non-ALCL cases. A summary of the FISH findings in all study groups is presented in Table 2.

Primary systemic ALCL ( $A L K+$ and $A L K-$ )

Rearranged 2p23 $A L K$ gene loci were present in biopsies from all $(n=6)$ ALK + ALCL patients (Figure 3a). Further, in two of these six cases, two extra $3^{\prime}$ telomeric ends of the rearranged $2 p 23$ locus were noted, suggesting the presence of a secondary cytogenetic aberration.

There was no rearrangement of the 2p23 ALK gene locus in the primary systemic ALK- ALCL cases $(n=5)$. However, there were extra nonrearranged 2 p23 loci (Figure 3b) due to extra copies of chromosome 2 within the lymphoma cells, as confirmed by using centromeric probes for chromosomes 2 (Figure 3c) and 10 in four cases with additional available sections. In all five cases, 40$80 \%$ of the lymphoma cells had one extra nonrearranged 2p23 signal. Two cases showed additional 39 nonrearranged 2 p23 signals in 1-5\% lymphoma cells. Of interest, two biopsies from one patient over a 4-month interval showed virtually identical findings (one extra nonrearranged 2p23 locus) at both times.

Primary cutaneous ALCL

There was no rearrangement of the 2 p23 ALK gene locus in the cutaneous ALCL cases $(n=7)$. However,

Table 2 Summary of FISH results

\begin{tabular}{|c|c|c|c|c|}
\hline Diagnosis & Total specimens & $\begin{array}{l}\text { Specimens with } \\
\text { successful FISH }\end{array}$ & $\begin{array}{c}\text { Specimens with } \\
\text { rearranged } \\
2 p 23 \text { ALK gene loci }\end{array}$ & $\begin{array}{c}\text { Specimens with extra } \\
\text { non-rearranged } 2 p 23 \\
\text { ALK gene loci }\end{array}$ \\
\hline \multicolumn{5}{|l|}{ Primary systemic ALCL } \\
\hline $\mathrm{ALK}+$ & 10 & 6 & 6 & 0 \\
\hline ALK- & 7 & $5^{\mathrm{a}}$ & 0 & $5^{\mathrm{a}, \mathrm{b}}$ \\
\hline Primary cutaneous ALCL & 7 & $7^{\mathrm{a}}$ & 0 & $5^{\mathrm{a}, \mathrm{b}}$ \\
\hline Diffuse large B-lineage lymphoma, ALK+ & 1 & 1 & 1 & 0 \\
\hline \multicolumn{5}{|l|}{ Diffuse large B-cell lymphoma, ALK- } \\
\hline Anaplastic variant, CD30+ & 5 & 5 & 0 & 2 \\
\hline Anaplastic variant, CD30- & 2 & 2 & 0 & 2 \\
\hline Non-anaplastic & 5 & 5 & 0 & 0 \\
\hline Secondary, CD30+ & $2^{\mathrm{c}}$ & $2^{\mathrm{d}}$ & $0^{\mathrm{d}}$ & $2^{\mathrm{e}}$ \\
\hline Follicular lymphoma, grade 1 & 2 & 2 & 0 & 0 \\
\hline Benign lymph nodes & 4 & 4 & 0 & 0 \\
\hline Total & 45 & 39 & 7 & 16 \\
\hline
\end{tabular}

\footnotetext{
${ }^{\mathrm{a}}$ Include two biopsies from one patient.

birtually identical findings in both biopsies from one patient.

${ }^{\mathrm{c}}$ Both composite lymphomas at presentation, one with nodular lymphocyte predominant Hodgkin lymphoma and one with follicular lymphoma, grade 1.

${ }^{\mathrm{d}}$ Also in the primary nodular lymphocyte predominant Hodgkin lymphoma component of one composite case.

${ }^{\mathrm{e}}$ Rare large cells in nodular lymphocyte predominant Hodgkin lymphoma component also showed extra nonrearranged 2p23 loci.
} 

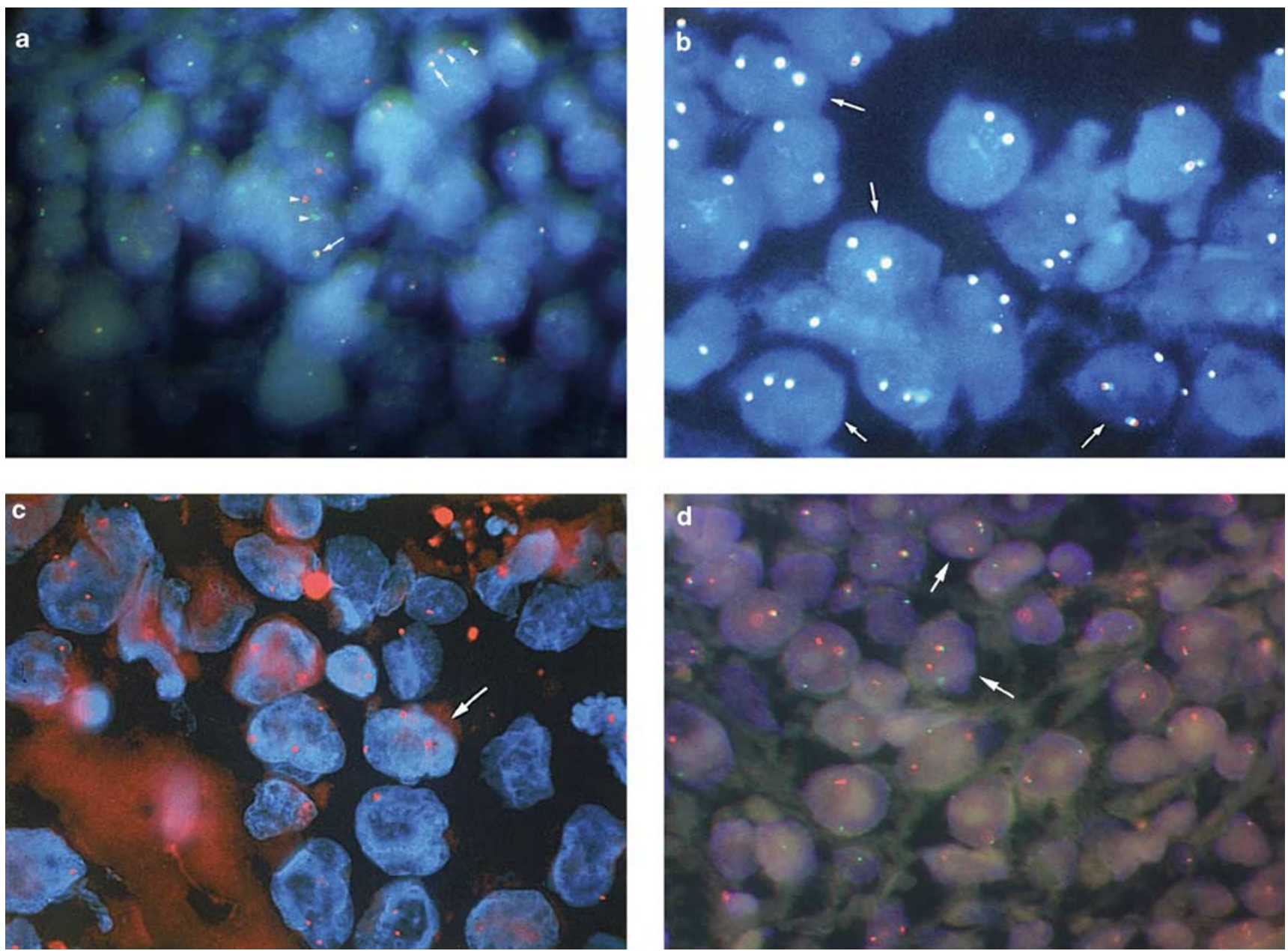

Figure 3 (a) FISH using the dual-color 2p23 LSI ALK locus-specific probe on paraffin-embedded section in a primary systemic ALCL $(\times 1500)$ showing distinct separation of the red and green signals (arrowheads) indicating a break (rearrangement) in the $2 \mathrm{p} 23$ anaplastic lymphoma kinase gene locus. The normal nonrearranged 2p23 locus (arrow) and one rearranged 2p23 locus (arrowheads) are indicated in two representative cells. (b) FISH using the dual-color 2p23 LSI ALK locus-specific probe on paraffin-embedded section in a primary systemic ALCL ( $\times 1500$ ) showing extra nonrearranged 2p23 loci in multiple lymphoma cells (arrows). (c) FISH using a centromeric probe for chromosome 2 on paraffin-embedded section in a primary systemic ALCL $(\times 1500)$ with extra nonrearranged 2 p23 signals, confirming the presence of trisomy 2 as the cause of extra nonrearranged 2 p23 loci in the lymphoma cells (a representative cell with arrow). (d) FISH using the dual-color 2p23 LSI ALK locus-specific probe on paraffin-embedded section in ALK + B-lineage lymphoma $(\times 1500)$ showing rearranged 2p23 loci (arrows).

in five cases, one extra nonrearranged 2p23 signal was detected in $15-25 \%$ of the lymphoma cells. Both the biopsies from one patient showed similar FISH findings (one extra nonrearranged 2p23 locus). Owing to the small diagnostic biopsies and depleted tissue in the sections studied by centromeric FISH probes, we could not confirm trisomy 2 by centromeric probes in the cutaneous ALCL cases.

\section{$A L K+$ diffuse large B-lineage lymphoma}

The $2 \mathrm{p} 23 A L K$ gene locus was rearranged in greater than $90 \%$ of the lymphoma cells in this one case (Figure 3d).

\section{Non-ALCL ALK-negative lymphomas and controls} All ALK - non-ALCL cases and controls were negative for $2 \mathrm{p} 23$ ALK gene locus rearrangement.
However, extra copies of non-rearranged 2p23 loci were detected in lymphoma cells of $66 \%(n=9)$ of ALK - diffuse large B-cell lymphomas with anaplastic morphology (2/5 CD30 + and 2/2 CD30- anaplastic variants, and $2 / 2$ secondary CD $30+$ ).

Extra nonrearranged 2p23 loci signals (1-3) due to extra copies of chromosome 2 were detected in about $20-40 \%$ of lymphoma cells in both of the $\mathrm{CD} 30+\mathrm{ALK}-$ diffuse large B-cell lymphoma, anaplastic variant cases. One of these two cases was HIV-associated; this case showed trisomy 10 in addition to trisomy 2, indicating a hyperdiploid karyotype of the lymphoma cells. One extra nonrearranged 2p23 locus due to trisomy 2 was detected in about $10-20 \%$ of lymphoma cells in both of the CD30- diffuse large B-cell lymphoma cases with anaplastic histologic features, while the number of 
Table 3 Summary of statistical analysis

\begin{tabular}{|c|c|c|}
\hline & \multicolumn{2}{|c|}{$\mathrm{P}$-values } \\
\hline & $\begin{array}{l}\text { Extra copies of } \\
\text { chromosome } 2\end{array}$ & $\begin{array}{l}\text { Rearranged } 2 p 23 \\
\text { ALK gene loci }\end{array}$ \\
\hline Anaplastic morphology & 0.004 & 1.000 \\
\hline Phenotype (B or T/null) & 0.315 & 0.088 \\
\hline WHO diagnostic category & 0.131 & 0.016 \\
\hline $\begin{array}{l}\text { CD30 positivity by } \\
\text { immunohistochemistry }\end{array}$ & 1.000 & 1.000 \\
\hline $\begin{array}{l}\text { ALK1 expression by } \\
\text { immunohistochemistry }\end{array}$ & 0.009 & $<\mathbf{0 . 0 0 1}$ \\
\hline $\begin{array}{l}\text { Rearranged 2p23 loci by } \\
\text { FISH }\end{array}$ & 0.009 & Not applicable \\
\hline Sex of patient & 0.250 & 1.000 \\
\hline
\end{tabular}

$P$-values $<0.05$ considered significant and are shown in bold. See text for WHO diagnostic categories.

nonrearranged 2p23 $A L K$ loci signals was normal in all nonanaplastic diffuse large B-cell lymphoma cases $(n=5)$.

Extra nonrearranged 2p23 loci due to trisomy 2 were detected in both of the secondary (composite) large B-cell lymphomas. In the composite case with nodular lymphocyte predominant Hodgkin lymphoma, rare large cells in this adjacent nodular Hodgkin component were noted to have extra nonrearranged 2p23 loci consistent with extra copies of chromosome 2 in the neoplastic cells.

\section{Statistical Analysis}

Table 3 shows a summary of the results of the tests of statistical significance. In all study cases, extra copies of chromosome 2 were significantly associated with anaplastic morphology $(P=0.004)$, without any significant association with the abovementioned WHO diagnostic categories $(P=0.131)$, B- or T/null cell phenotype $(P=0.315)$, CD30 positivity $(P=1.000)$, or with the sex of the patient $(P=0.250)$. Extra copies of chromosome 2 were not associated with ALK1 positivity by immunohistochemistry $(P=0.009)$ or rearranged $2 \mathrm{p} 23 A L K$ gene loci $(P=0.009)$.

In contrast, rearranged 2p23 $A L K$ gene loci were invariably associated with ALK1 immunopositivity $(P<0.001)$, and showed significant association with the above-mentioned diagnostic categories $(P=0.016)$. The rearranged $2 \mathrm{p} 23$ loci were not significantly associated with anaplastic morphology $(P=1.000)$, B- or $\mathrm{T} /$ null cell phenotype $(P=0.088)$, and CD30 expression $(P=1.000)$.

\section{Discussion}

Karyotypic abnormalities in lymphomas are generally much more complex as compared with leukemias. ${ }^{29}$ These complex karyotypes include secondary abnormalities that are less specific than the primary abnormality, and are believed to reflect clonal evolution during tumor progression. ${ }^{30}$ When a cytogenetic anomaly, such as the $N P M-A L K$ gene translocation in $\mathrm{t}(2 ; 5)(\mathrm{p} 23 ; \mathrm{q} 35)$ is the only change within neoplastic cells, it is thought to play a fundamental role in the initiation of the neoplastic process. While the NPM-ALK gene translocation is a necessary but insufficient event in the genesis of ALK + ALCL, ${ }^{31-33}$ little is known about the secondary cytogenetic or molecular genetic changes that lead to either cellular transformation in ALK+ ALCL or to ALK - systemic or cutaneous ALCL. ${ }^{34}$

We observed extra copies of chromosome 2 as a recurring abnormality in all ALK - primary systemic ALCL $(n=5)$ and $70 \%$ cutaneous ALCL $(n=7)$ by FISH performed on paraffin-embedded tissue sections. Two ALCL recurrences examined were similar to their primary biopsies, indicating that increased copy number of chromosome 2 is not a random event in ALCL. This increased copy number of chromosome 2 in ALCL is most likely due to trisomy 2 since extra copies of chromosome 10 were absent in all but one case. We do not know whether this aberration is involved in initiation or progression of ALK - ALCL; it would be of interest to know the entire chromosomal constitution in our cases. In either situation, the present findings of trisomy 2 in the secondary B-cell lymphomas suggest that this aberration is not specific to ALCL and may represent a general secondary cytogenetic change in lymphomas. Extra copies of chromosome 2 are not uncommon in lymphomas, and have been reported in Hodgkin and non-Hodgkin lymphomas of $\mathrm{B}$ and $\mathrm{T}$ phenotype ${ }^{34}$ strengthening the idea that trisomy 2 may be a secondary cytogenetic aberration in ALCL.

Our study suggests that extra copies of chromosome 2 may be used as an additional marker to distinguish ALK - and ALK + ALCL, since none of our ALK + cases showed trisomy 2. A review of the literature identifies additional copies of chromosome 2 in four systemic ALCL cases, which include three ALK + cases with variant translocations, and in two cutaneous ALCL cases, but they appear to be extremely rare in ALCL with the $\mathrm{t}(2 ; 5)$ translocation. ${ }^{34}$ We do not know whether there is a biological property that is inherent to ALK + lymphomas that prevents duplication of chromosome 2 . Whatever the mechanism, while trisomy 2 does not appear to be a frequent secondary event in the pathogenesis of ALK + ALCL, it is a common finding in ALKlymphomas with anaplastic morphology.

Two recent studies examined genomic alterations in primary cutaneous and systemic ALK- ALCL by comparative genomic hybridization. ${ }^{35,36}$ Firstly, Mao et $a l^{35}$ have reported oncogene copy number gains that include the REL (2p13p12) and $M Y C-N(2 \mathrm{p} 24.1)$ genes in six $(75 \%)$ and four $(50 \%)$ of their cutaneous ALCL cases, respectively. Secondly, in a study of Tcell lymphomas, Zettl et $a l^{36}$ found imbalances of chromosome 2 in five (29\%) nodal/systemic ALCL 
and none of 11 cutaneous ALCL cases. They also reported solitary amplifications of 2cen-p22 or imbalances of chromosome 2 in 15 (36\%) cases of peripheral T-cell lymphoma, unspecified by WHO criteria. These reports lend support to gains of chromosome $2 \mathrm{p}$ in ALK- T-cell lymphomas in general. Additional studies are necessary, however, to determine if there truly is a homogeneous difference between the genetic aberrations in cases classified as ALK- ALCL and ALK- peripheral Tcell lymphomas, unspecified by WHO criteria.

In conclusion, trisomy 2 occurs frequently in ALK- lymphomas with anaplastic morphology, including primary systemic ALK- and primary cutaneous ALCL. Whether it represents a primary or a secondary cytogenetic aberration in the clonal evolution of ALK - ALCL cannot be determined from this study. Additional studies beyond the scope of the current study would be required to elucidate the underlying molecular mechanism(s), and to ascertain the significance of trisomy 2 in the pathogenesis of this heterogeneous group of lymphomas.

\section{Acknowledgements}

We are deeply grateful to Dr JJ Brooks, former Chairman of the Department of Pathology at Roswell Park Cancer Institute for his support towards this project. We thank Joyce Bailey and Elizabeth Stachewicz for their excellent assistance with the immunohistochemical stains, and $\mathrm{Dr}$ Bertram Schnitzer for his critical review of the manuscript. We do not have any duality of interest to declare.

\section{References}

1 Stein H, Mason DY, Gerdes J, et al. The expression of the Hodgkin's disease associated antigen Ki-1 in reactive and neoplastic lymphoid tissue: evidence that Reed-Sternberg cells and histiocytic malignancies are derived from activated lymphoid cells. Blood 1985; 66:848-858.

2 Chan JKC, Ng CS, Hui PK, et al. Anaplastic large cell Ki-1 lymphoma: delineation of two morphological types. Histopathology 1989;15:11-34.

3 Kadin ME. Anaplastic large cell lymphoma and its morphological variants. Cancer Surv 1997;30:77-86.

4 Kinney MC, Collins RD, Greer JP, et al. A small cell predominant variant of primary Ki-1 (CD30)+ T-cell lymphoma. Am J Surg Pathol 1993;17:859-868.

5 Pileri S, Falini B, Delsol G, et al. Lymphohistiocytic T-cell lymphoma (anaplastic large-cell lymphoma) CD30-Ki-1+ with a high content of reactive histiocytes. Histopathology 1990;16:383-391.

6 Chan JK, Buchanan R, Fletcher CD. Sarcomatoid variant of anaplastic large cell Ki-1 lymphoma. Am J Surg Pathol 1990;14:983-988.

7 Mann KP, Hall B, Kamino H, et al. Neutrophil-rich, Ki-1 positive anaplastic large cell malignant lymphoma. Am J Surg Pathol 1995;19:407-416.
8 Falini B, Liso A, Pasqualucci L, et al. CD30+ anaplastic large cell lymphoma, null type, with signet-ring appearance. Histopathology 1997;30:90-92.

9 Benharroch D, Meguerian-Bedoyan Z, Lamant L, et al. ALK-positive lymphoma: a single disease with a broad spectrum of morphology. Blood 1998;91:2076-2084.

10 Kinney MC, Kadin ME. The pathologic and clinical spectrum of anaplastic large cell lymphoma and correlation with ALK gene dysregulation. Am J Clin Pathol 1999;111(Suppl 1):S56-S67.

11 Stein H, Foss H-D, Durkop H, et al. CD30+ anaplastic large cell lymphoma: a review of its histopathologic, genetic, and clinical features. Blood 2000;96:36813695.

12 Harris NL, Jaffe ES, Stein H, et al. A revised EuropeanAmerican classification of lymphoid neoplasms: a proposal from the International Lymphoma Study Group. Blood 1994;84:1361-1392.

13 Jaffe ES, Harris NL, Stein H, et al (eds). World Health Organization Classification of Tumours. Pathology and Genetics of Tumours of Hematopoietic and Lymphoid Tissues. IARC Press: Lyon, 2001.

14 Falini B, Bigerna B, Fizzotti M, et al. ALK expression defines a distinct subgroup of $\mathrm{T} / \mathrm{null}$ lymphomas ('ALK lymphomas') with a wide morphological spectrum. Am J Pathol 1998;153:875-886.

15 Gascoyne RD, Aoun $\mathrm{P}, \mathrm{Wu} \mathrm{M}$, et al. Prognostic significance of anaplastic large cell lymphoma kinase (ALK) protein expression in adults with anaplastic large cell lymphoma. Blood 1999;93:3913-3921.

16 Shiota M, Nakamura S, Ichinohasama $\mathrm{R}$, et al. Anaplastic large cell lymphomas expressing the novel chimeric protein p80NPM/ALK: a distinct clinicopathologic entity. Blood 1995;86:1954-1960.

17 Lennert K, Feller AC. Histopathology of NonHodgkin's Lymphomas, 2nd edn. Springer-Verlag: New York, 1992.

18 Haralambieva E, Pulford KA, Lamant L, et al. Anaplastic large cell lymphomas of B-cell phenotype are anaplastic lymphoma kinase (ALK) negative and belong to the spectrum of diffuse large B-cell lymphomas. Br J Haematol 2000;109:584-591.

19 Delsol G, Lamant L, Mariamé B, et al. A new subtype of large B-cell lymphoma expressing the ALK kinase and lacking the 2;5 translocation. Blood 1997;89: 1483-1490.

20 De Paepe P, Baens M, van Krieken $\mathrm{H}$, et al. ALK activation by the CTLC-ALK fusion is a recurrent event in large B-cell lymphoma. Blood 2003;102: 2638-2641.

21 Gascoyne RD, Lamant L, Martin-Subero JI, et al. ALKpositive diffuse large B-cell lymphoma is associated with Clathrin-ALK rearrangements: report of six cases. Blood 2003;102:2568-2573.

22 Onciu M, Behm FG, Downing JR, et al. ALK-positive plasmablastic B-cell lymphoma with expression of the NPM-ALK fusion transcript: report of two cases. Blood 2003;102:2642-2644.

23 Falini B, Pulford K, Pucciarini A, et al. Lymphomas expressing ALK fusion protein(s) other than NPMALK. Blood 1999;94:3509-3515.

24 Touriol C, Greenland C, Lamant L, et al. Further demonstration of the diversity of chromosomal changes involving 2p23 in ALK-positive lymphoma: two cases expressing ALK kinase fused to CTLC (clathrin chain polypeptide-like). Blood 2000;95: 3204-3209. 
25 Duyster J, Bai RY, Morris S. Translocations involving anaplastic lymphoma kinase (ALK). Oncogene 2001; 20:5623-5637.

26 Kutok JL, Aster JC. Molecular biology of anaplastic lymphoma kinase-positive anaplastic large-cell lymphoma. J Clin Oncol 2002;20:3691-3702.

27 Sundeen JT, Cossman J, Jaffe ES. Lymphocyte predominant Hodgkin's disease nodular subtype with coexistent 'large cell lymphoma': histologic progression or composite malignancy? Am J Surg Pathol 1988; 12:599-606.

28 Poppema S. Nodular lymphocyte predominance type of Hodgkin's disease. In: Weiss LM (ed). Pathology of Lymph Nodes. Churchill Livingstone: Edinburgh, 1996, pp 215-228.

29 Mrózek K, Bloomfield CD. Major cytogenetic findings in non-Hodgkin's lymphoma. In: Cannelos GP, Lister TA and Sklar JL (eds). The Lymphomas. WB Saunders: Philadelphia, PA, 1998, pp 107-128.

30 Heim S, Mitelman F. Cancer Cytogenetics, 2nd edn. Alan R Liss: New York, 1995.

31 Trumper L, Pfreundschuh M, Bonin FV, et al. Detection of the $t(2 ; 5)$-associated NPM/ALK fusion cDNA in peripheral blood cells of healthy individuals. $\mathrm{Br}$ Haematol 1998;103:1138-1144.

32 Maes B, Vanhentenrijk V, Wlodarska I, et al. The NPMALK and the ATIC-ALK fusion genes can be detected in non-neoplastic cells. Am J Pathol 2001;158: 2185-2193.

33 Kuefer MU, Look AT, Pulford K, et al. Retrovirus-mediated gene transfer of NPM-ALK causes lymphoid malignancy in mice. Blood 1997;90: 2901-2910.

34 Mitelman F, Johansson B, Mertens F (eds). Mitelman Database of Chromosome Aberrations in Cancer. Available at http://cgap.nci.nih.gov/Chromosomes/ Mitelman Accessed June 15, 2004.

35 Mao X, Orchard G, Lillington DM, et al. Genetic alterations in primary cutaneous CD30+ anaplastic large cell lymphoma. Genes Chromosomes Cancer 2003;37:176-185.

36 Zettl A, Rudiger T, Konrad M-A, et al. Genomic profiling of peripheral T-cell lymphoma, unspecified, and anaplastic large T-cell lymphoma delineates novel recurrent chromosomal alterations. Am J Pathol 2004; 164:1837-1848. 